\title{
Produtos Alimentares Locais como Vetores da Experiência Turística: uma revisão da literatura
}

Local Food Products as Vectors of the Tourist Experience: a literature review Productos alimentícios locales como vectores de la experiência turística: uma revisión de literatura

Recebido: 02/05/2020 | Revisado: 04/05/2020 | Aceito: 06/05/2020 | Publicado: 12/05/2020

\section{Renata Ramos Vieira dos Reis} ORCID: https://orcid.org/0000-0003-1055-0551 Instituto Federal de Educação, Ciência e Tecnologia Baiano, Brasil E-mail: renata.reis@ifbaiano.edu.br

\section{Resumo}

O consumo de alimentos locais pode ser considerado benéfico para o desenvolvimento da atividade turística e pode atrair visitantes para um destino, a fim de vivenciar experiências turísticas e gastronômicas. Neste contexto, o presente artigo pretende analisar a produção científica no que se refere às questões relacionadas aos alimentos locais como vetores da experiência turística e identificar as principais lacunas encontradas nesses estudos, no período compreendido entre os anos de 2003 a 2019. Para isso foram selecionados estudos a partir da base de dados SCOPUS por meio da combinação de palavras-chave "experienc*" and "local food" and "touris*". Desse modo, constatou-se que a gastronomia local pode ser importante fonte de receita para os destinos turísticos, além de representar e transmitir a cultura de um local, proporcionando aos turistas experiências memoráveis. Verificou-se também que as principais lacunas existentes nos estudos se referem principalmente às questões metodológicas, sugerindo que outros estudos sejam realizados em outras regiões geográficas, com diferentes populações e com um número maior de entrevistados, para melhorar a compreensão das emoções provocadas pelo consumo de comida local (culinária). Sugere-se ainda que sejam incluídos métodos qualitativos, como entrevistas com grupos focais para complementar a falta de informação em uma pesquisa quantitativa. Assim, o artigo apresenta uma revisão sistemática da literatura encontrada sobre a temática em análise.

Palavras-chave: Turismo; Comida local; Gastronomia; Experiência. 


\section{Abstract}

The consumption of local foods can be considered beneficial for the tourist activity development and can attract visitors to a destination, in order to experience tourist and gastronomic experiences. In this context, this article proposes to analyze the scientific production regarding to issues which refer local foods as vectors of the tourist experience, and to identify the main gaps found in these studies, between 2003 and 2019. The studies were selected from the SCOPUS database through the combination of keywords "experienc *" and "local food" and "touris *". Thus, it was found that local cuisine can be an important income source for tourist destinations, besides representing and transmitting the local culture, providing memorable experiences for tourists. It was also found that the main gaps in the studies relate mainly to methodological issues, suggesting that other studies with different populations and with a larger number of respondents should be carried out, aiming to improve the understanding of emotions caused by consumption of local food (cookery). It is also suggested that qualitative methods should be included, such as interviews with focal groups to complement the information lack in a quantitative survey. Thus, this article presents a systematic review of the available literature on the subject under analysis.

Keywords: Tourism; Local food; Gastronomy; Experience.

\section{Resumen}

El consumo de alimentos locales puede ser considerado beneficioso para el desarrollo de la actividad turística y puede atraer visitantes a un destino en busca de experiencias turísticas y gastronómicas. En este contexto, el presente artículo se propone a analizar la producción científica con respecto a cuestiones que relacionan los alimentos locales como vectores de la experiencia turística e identificar las principales brechas encontradas en esos estudios, de los años 2003 a 2019. Los estudios fueron colectados de la base de datos SCOPUS mediante la combinación de las palabras clave "experienc *" y "comida local" y "touris *". Así, se comprobó que la cocina local puede ser una fuente importante de ingresos para los destinos turísticos, además de representar y transmitir la cultura de un lugar, proporcionando experiencias memorables a los turistas. También se constató que las principales brechas en los estudios se refieren principalmente a cuestiones metodológicas, lo que sugiere que otros estudios en otras regiones geográficas, con diferentes poblaciones y con mayor número de encuestados deberían llevarse a cabo para mejorar la comprensión de las emociones causadas por el consumo de comida local (cocina). También se sugiere incluir métodos cualitativos, como entrevistas con grupos focales para complementar la falta de información en una 
encuesta cuantitativa. Por lo tanto, el artículo presenta una revisión sistemática de la literatura disponible sobre el tema en análisis.

Palabras clave: Turismo; Gastronomía local; Gastronomía; Experiencia.

\section{Introdução}

A atividade turística vem evoluindo ao longo dos anos e com isso, nota-se uma grande competitividade entre os destinos turísticos, que estão sempre em busca de atrair turistas para seus territórios. Por outro lado, esses turistas estão cada vez mais: seletivos, participativos e, bem informados quanto aos destinos que irão escolher. Eles querem destinos turísticos que além de uma infraestrutura de apoio, pensem de maneira sustentável, inovem nos seus serviços e tecnologias, que possam aliar experiências gastronômicas, históricas e culturais com atividades específicas daquela localidade, e acima de tudo que possa proporcionar experiências memoráveis e inesquecíveis.

Como um dos elementos essenciais à atividade turística, alguns pesquisadores observam que muitos destinos turísticos utilizam cada vez mais a gastronomia como uma iniciativa popular no desenvolvimento do turismo local. Para Aguiar \& Melo (2020), a gastronomia local une tradição, cultura, história, costumes, imersos a um patrimônio imaterial, cujos efeitos se observam no fenômeno turístico, satisfazendo uma demanda de consumidores cheios de expectativas pela viagem.

Há um conjunto de benefícios atrelados aos alimentos locais em um destino. Em particular, a comida local possui um alto potencial para contribuir para o desenvolvimento do turismo sustentável local (Chen \& Huang, 2019).

A comida local é uma maneira sustentável de prolongar a estadia turística e de aumentar os gastos de seus consumidores, que estarão apoiando a economia local, promovendo a produção local de alimentos, gerando receitas e provavelmente mantendo os ganhos do turismo naquela região.

Ajudam também no desenvolvimento da sustentabilidade ambiental de um destino, pois os turistas que consomem destes alimentos locais estão favorecendo o mercado local e estimulando a diversificação da agricultura local, que será preservada. E por fim, ajudam a melhorar a sustentabilidade social e cultural de um destino, pois representam o lugar e a cultura local (idem).

Como visto o consumo de alimentos locais além de benefícios para o desenvolvimento da atividade turística, pode atrair visitantes para uma localidade, a fim de vivenciar 
experiências gastronômicas. Para Wijaya, King, Nguyen, \& Morrison (2013), as evidências de vários estudos indicaram que o interesse do visitante e as preferências por alimentos nos locais de destino podem ser um determinante significativo das escolhas de destino. Enquanto isso, Kivela \& Crotts (2006), Nield, Kozak\& LeGrys (2000), e Ryu \& Jang (2006), citados por Wijaya et al. (2013), postulam a influência das experiências alimentares na percepção dos visitantes, satisfação e intenções de revisitar o destino. Além disso, é possível observar que a comida atua como um meio para os visitantes conhecerem mais sobre outra cultura através de um envolvimento direto com as culinárias locais em um destino, que difere do que eles têm em casa. A comida local pode servir como um meio de ajudar os visitantes a apreciar a cultura que prevalece em um destino, tornando a experiência memorável.

Desse modo, percebe-se que os estudos que têm sido publicados sobre a temática 'os alimentos locais como vetores da experiência turística' podem ser categorizados prioritariamente em três grupos: (i) estudos que analisam os alimentos locais como influenciadores da experiência turística; (ii) estudos que avaliam os alimentos locais como indutores do desenvolvimento da atividade turística; e (iii) estudos que analisam as motivações para compra de alimentos locais e para retorno ao destino.

Este artigo pretende analisar estudos científicos produzidos entre os anos de 2003 até 2019, no que concerne às questões relacionadas à influência do alimento local no comportamento dos visitantes de áreas turísticas e a importância que os alimentos locais exercem no desenvolvimento da atividade turística, buscando identificar, em termos de pesquisa, as possíveis lacunas que ainda existem nessa temática.

Verificou-se que sobre essa temática existem poucos estudos de revisão de literatura, apenas dois, porém, não existe ainda nenhum artigo de revisão sistemática da literatura publicado, que identifique especificamente as lacunas existentes nos estudos. Assim, no intuito de atingir este objetivo, este artigo apresenta: a) a metodologia utilizada para selecionar os trabalhos que estiveram na base da análise realizada; b) os resultados encontrados nos estudos selecionados, e por último, c) as conclusões e sugestões para estudos futuros. Portanto, este trabalho fará uma análise da revisão sistemática de literatura, no intuito de contribuir para o aumento do conhecimento nessa área.

\section{Metodologia}

Uma pesquisa, como preconiza Pereira et al. (2018) visa trazer novos conhecimentos ou saberes. Neste artigo buscou-se analisar as investigações que têm sido publicadas sobre a 
temática 'os alimentos locais como vetores da experiência turística'. Desse modo, realizou-se uma pesquisa na base de dados científica SCOPUS, durante o mês de abril de 2019. Como resultado, obtiveram-se 99 documentos publicados, utilizando-se a combinação de palavraschave: (experienc* and "local food") and (touris*), pesquisando nos campos 'title, abstract and keywords', não limitando a área de pesquisa nem o tipo de documento, porém 41,7\% dos documentos se concentram na área de 'Business, Management and Accounting' e 24\% na área ‘ Social Sciences', e 84, 8\% deles são artigos e 7,1\% capítulo de livro. Quanto ao período pesquisado, não houve restrição, sobretudo só apareceram pesquisas publicadas entre os anos de 2003 e 2019. O idioma da pesquisa também não foi limitado, conforme protocolo de pesquisa apresentado na Tabela 1.

Tabela 1. Protocolo de Pesquisa Utilizado.

\begin{tabular}{|l|l|}
\hline \multicolumn{2}{|c|}{ Protocolo de Pesquisa Utilizado } \\
\hline Base & Scopus \\
\hline Palavras-chave & Experienc*, local food, touris* \\
\hline Horizonte temporal & Sem restrição de tempo \\
\hline Área de Estudo & Todas \\
\hline Tipo de Documento & Sem delimitação \\
\hline Idioma & Sem delimitação \\
\hline
\end{tabular}

Fonte: Elaborado pela autora

Para este trabalho, a seleção dos artigos pesquisados iniciou a partir da leitura dos seus abstracts e objetivos. Desta forma foi possível avaliar se o artigo estava dentro da temática pesquisada, se era relevante para a pesquisa em termos de contributos conceituais e se estavam disponíveis para download em suas versões completas.

Assim, resultaram vinte artigos, que foram lidos $\mathrm{e}$ analisados na íntegra $\mathrm{e}$ posteriormente feitos fichamento, em tabela do Excel, para facilitar a visualização das principais informações (título, autor, palavras-chave, revista, país/região, objetivos, teorias/conceitos, metodologia da coleta de dados, metodologia da análise de dados, principais resultados, conclusões, limitações e investigação futura). Partindo das análises realizadas nos estudos selecionados, foram encontrados alguns resultados apresentados a seguir. 


\section{Resultados e Discussão}

\subsection{Resultados encontrados}

Este artigo tem como objetivo analisar de forma sistemática a produção científica sobre a temática que envolve as questões relacionadas às experiências gastronômicas com alimentos locais, e suas implicações, em destinos turísticos.

O horizonte temporal da pesquisa foi de 2003 até 26 de abril de 2019. Justifico a escolha desse período, pois foi quando surgiu a primeira pesquisa publicada na SCOPUS sobre a temática e 26 de abril de 2019 por ter sido o dia da pesquisa realizada.

Apresentam-se, a seguir, os resultados mais detalhados sobre os principais autores, países e meios de publicação, áreas publicadas, anos de publicação e tipos de documento. Vale ressaltar que esses resultados são referentes à pesquisa com 99 estudos apresentados. Posteriormente serão apresentados também alguns resultados mais específicos, referentes aos 20 artigos selecionados pela relevância e aderência ao tema em análise.

\subsubsection{Evolução dos artigos}

$\mathrm{Na}$ pesquisa realizada, tendo como base as palavras-chave selecionadas, foram encontrados 99 documentos relacionados, compreendidos entre o período de 2003 a 2019, dentre eles: artigos, capítulos de livros, anais de eventos, dentre outros.

Os anos que reuniram uma maior produção científica na área pesquisada foram os de 2017 (dezenove artigos), 2018 (dezessete artigos), 2019 e 2013 (dez artigos cada) e 2016 e 2015 (nove artigos cada), revelando ser um tema estudado há pouco tempo, como mostra a Figura 1.

Vale ressaltar que o ano de 2019 (a pesquisa foi realizada em abril de 2019), haviam sido publicados 10 artigos, o que leva a crer que esse número pode se elevar. 
Figura 1. Resultados da pesquisa por ano.

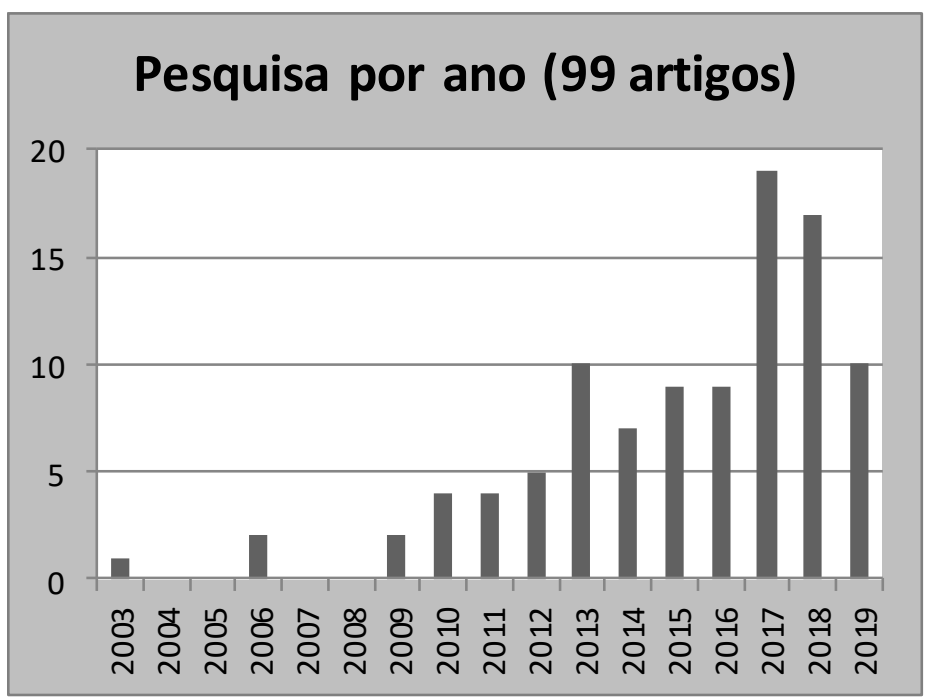

Fonte: Elaborado pela autora.

Dos 20 artigos selecionados, os mais antigos são do ano de 2013, com 3 artigos publicados, como mostra a Figura 2.

Figura 2. Resultados da pesquisa por ano.

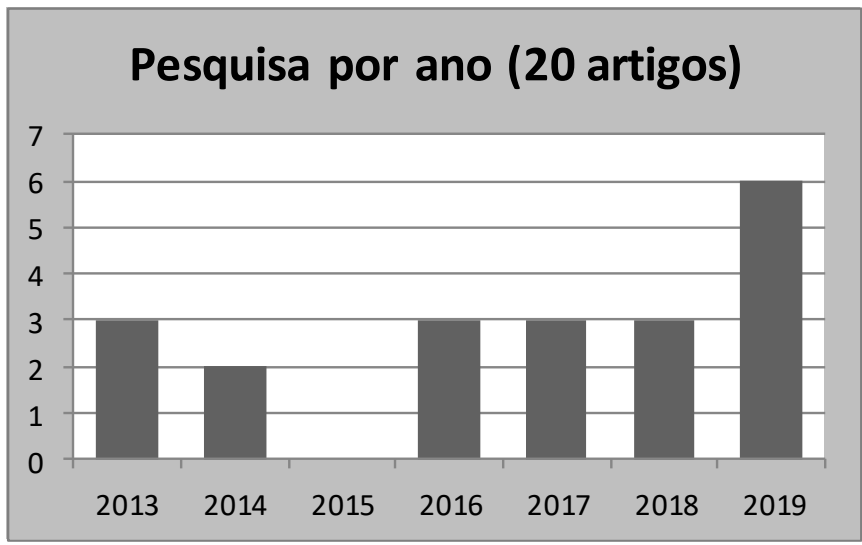

Fonte: Elaborado pela autora.

Observa-se que este fato reforça a ideia de que o tema pesquisado é bastante recente e com potencial para novos estudos. Porém, dentre esta seleção, o ano que teve mais estudos publicados foi o de 2019, com 6 estudos. Vale lembrar novamente que a pesquisa foi realizada no mês de abril de 2019, e que esse número de publicações pode se elevar. 


\subsubsection{Principais meios de publicação sobre o tema}

Ainda segundo a pesquisa realizada na SCOPUS, os principais meios de publicação foram as revistas científicas: Tourism Management (oito), International Journal of Hospitality (sete), Journal of Sustainable Tourism (cinco), Anatolia (quatro), Scandinavian Journal of Hospitality and Tourism (quatro), Tourism Management Perspectives (quatro), e os demais em outras revistas com pouca representatividade em números de publicações (uma ou duas por revista), como mostra a Figura 3.

Figura 3. Distribuição dos artigos dedicados ao tema geral em análise, em revistas científicas com maior representatividade.

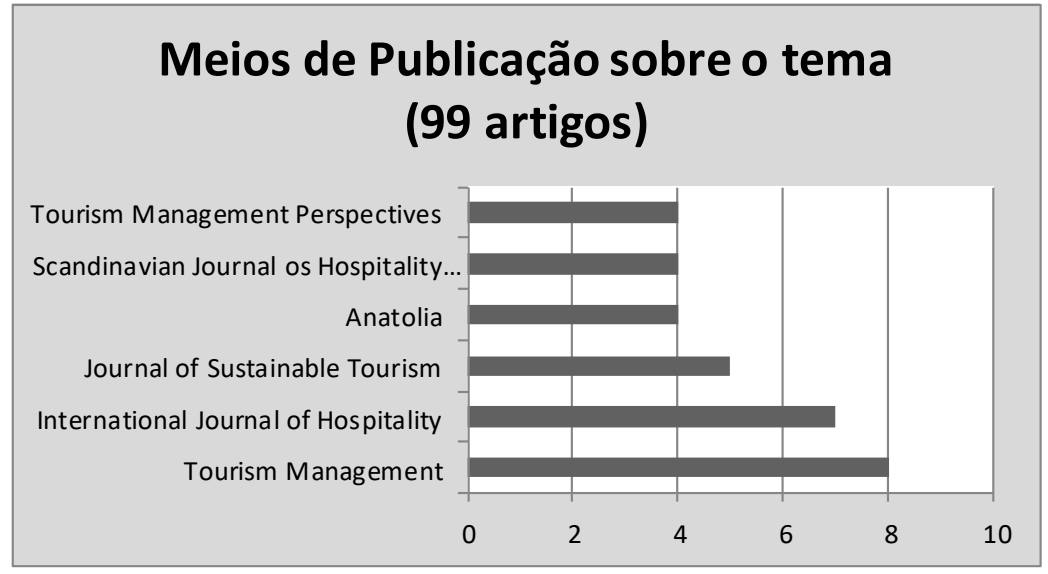

Fonte: Elaborado pela autora.

Fazendo uma análise comparativa dos principais meios de publicação sobre o tema, na pesquisa dos 99 estudos e na pesquisa dos 20 artigos (Figura 4), direcionada ao tema específico.

Figura 4. Distribuição dos artigos dedicados ao tema específico em análise, em revistas científicas com maior representatividade.

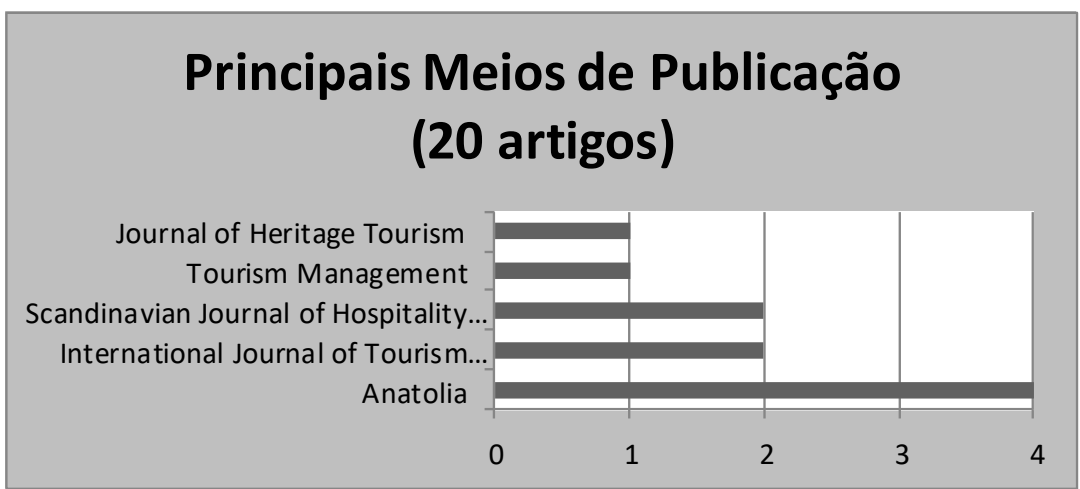

Fonte: Elaborado pela autora. 
Pode-se dizer que a revista Tourism Manegement, que foi a mais representativa na pesquisa geral, com 8 artigos, na pesquisa direcionada, poderia ter sido considerada irrelevante, pois apareceu com apenas 1 artigo publicado. Já a revista Anatolia foi a que mais publicou sobre o tema na pesquisa direcionada, com 4 artigos.

\subsubsection{Documentos por Autores}

Os autores que mais publicaram sobre a temática pesquisada foram Peter Björk, com 6 artigos, que tratam principalmente dos fatores que contribuem para as experiências gastronômicas dos viajantes que consomem alimentos locais.

Erose Sthapit publicou 5 artigos relacionados ao tema, sobretudo tratando de examinar a influência das emoções do consumo de alimentos locais na memória dos turistas.

E Hannele Kauppinen-Räisänen, que escreve em parceria com outros autores, publicou 4 estudos, também sobre os fatores que afetam o comportamento dos viajantes relacionados aos alimentos locais (Figura 5).

Figura 5. Documentos por autor - Pesquisa geral.

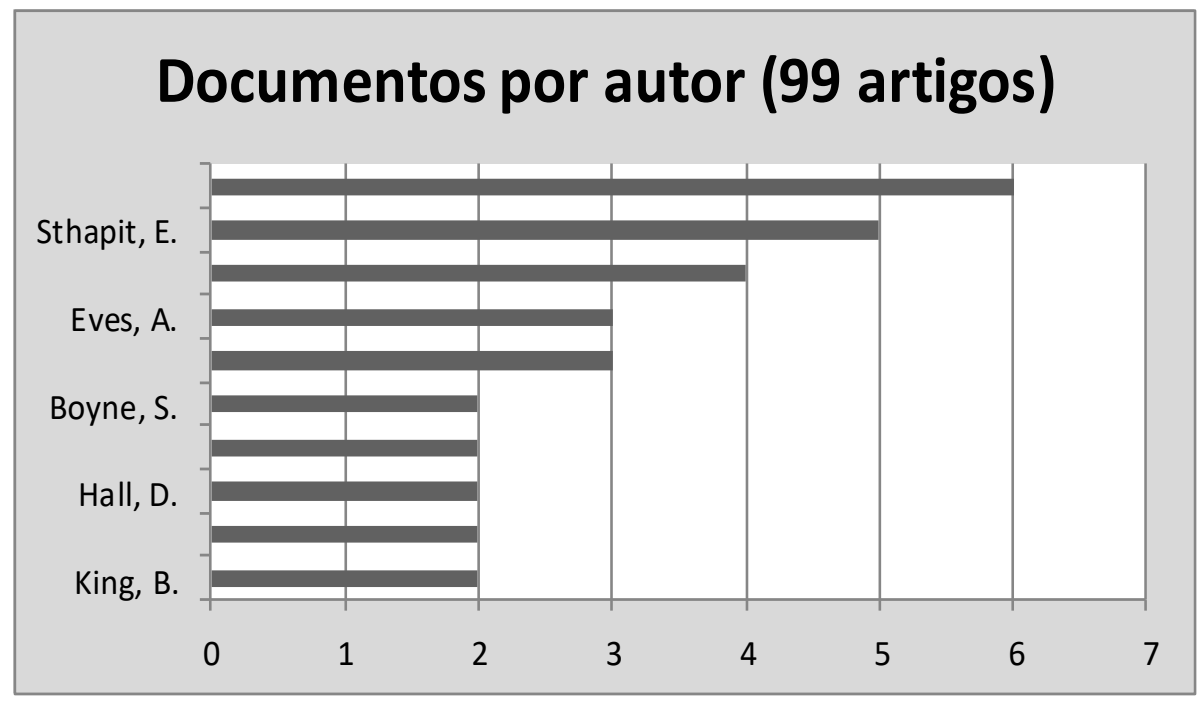

Fonte: Elaborado pela autora.

$\mathrm{Na}$ pesquisa direcionada ao tema específico, foi confirmada a soberania dos autores Peter Björk, Erose Sthapit e Hannele Kauppinen-Räisänen como os estudiosos que mais publicam sobre o tema (Figura 6). 
Figura 6. Documentos por autor - Pesquisa direcionada.

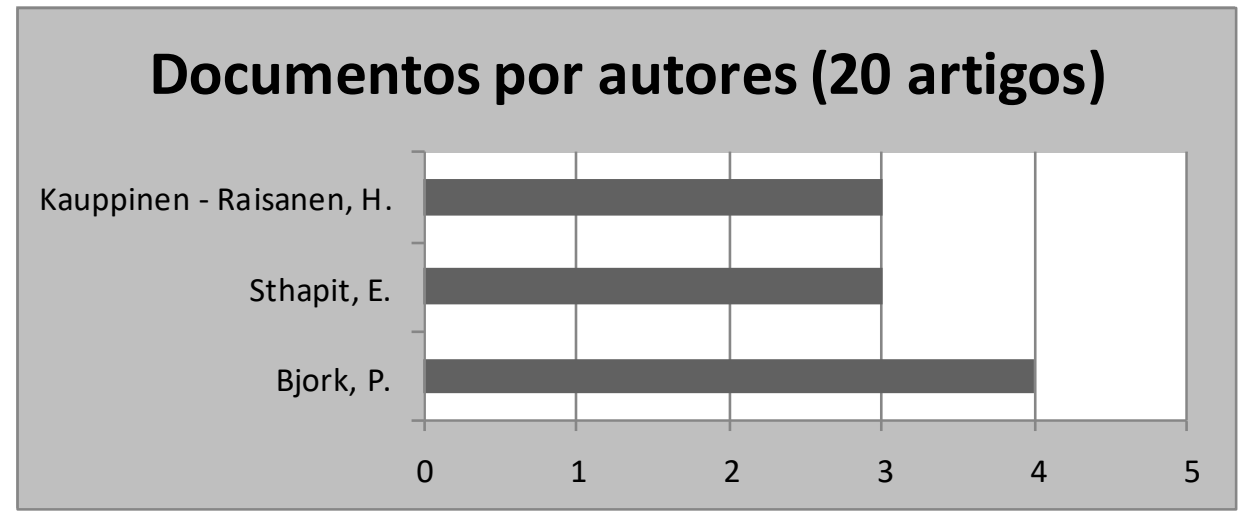

Fonte: Elaborado pela autora

\subsubsection{Documentos Publicados por País}

Na pesquisa geral com as palavras-chave, que resultou em 99 artigos selecionados, os países que mais se destacaram em termos de publicações científicas foram: Reino Unido com 15 estudos, Finlândia com 11, Austrália e Estados Unidos com 10 cada (Figura 7). Já a pesquisa mais direcionada aos objetivos preteridos, que resultou nos 20 artigos selecionados, mostra que a Finlândia se destaca com 6 artigos publicados. O que revela que dentro da temática específica pretendida, a Finlândia se sobressai com estudos que tratam das emoções do consumo de alimento local na memória dos turistas (Figura 8).

Figura 7. Pesquisa geral (99 docs).

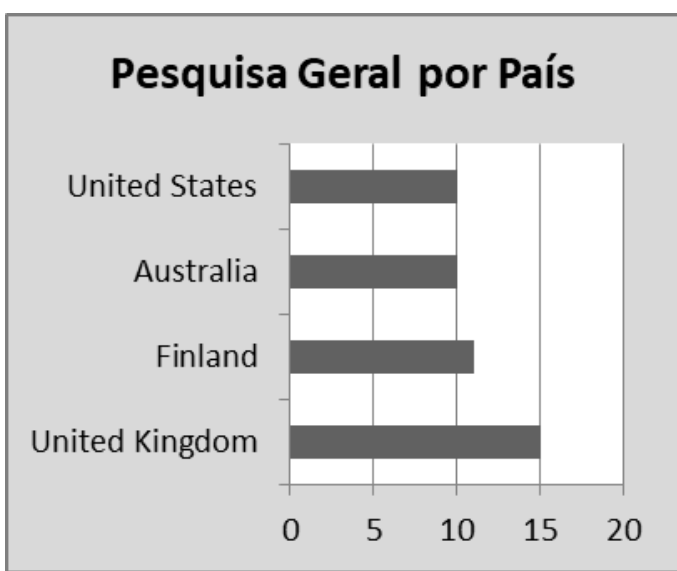

Fonte: Elaborado pela autora
Figura 8. Pesquisa refinada (20 docs).

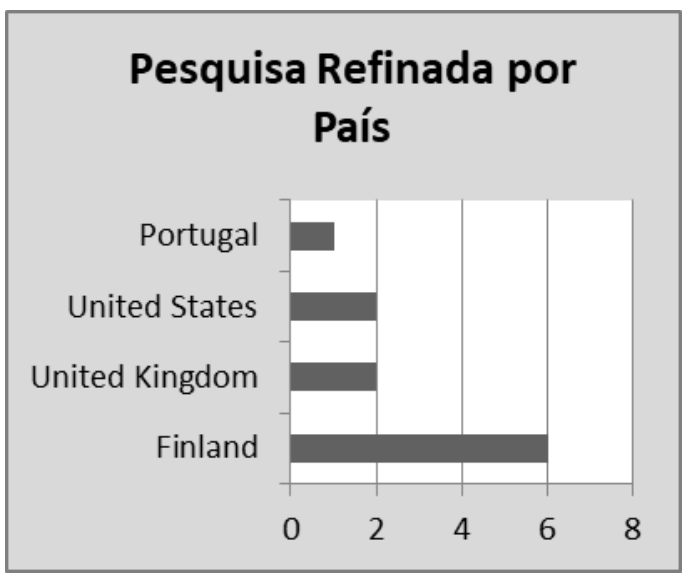

Fonte: Elaborado pela autora 


\subsubsection{Documentos Publicados por Tipo}

Verificam-se na pesquisa geral, com os 99 artigos, que os números mais expressivos quanto ao tipo de documentos publicados foram: 84,8\% dos documentos publicados correspondem a artigos científicos, $7,1 \%$ a capítulo de livros, seguidos de $3 \%$ de anais de eventos, como mostra a Figura 9. Na pesquisa direcionada aos estudos selecionados (20 artigos), mostrou que todos eram artigos publicados em revistas científicas.

Figura 9. Documento por tipo.

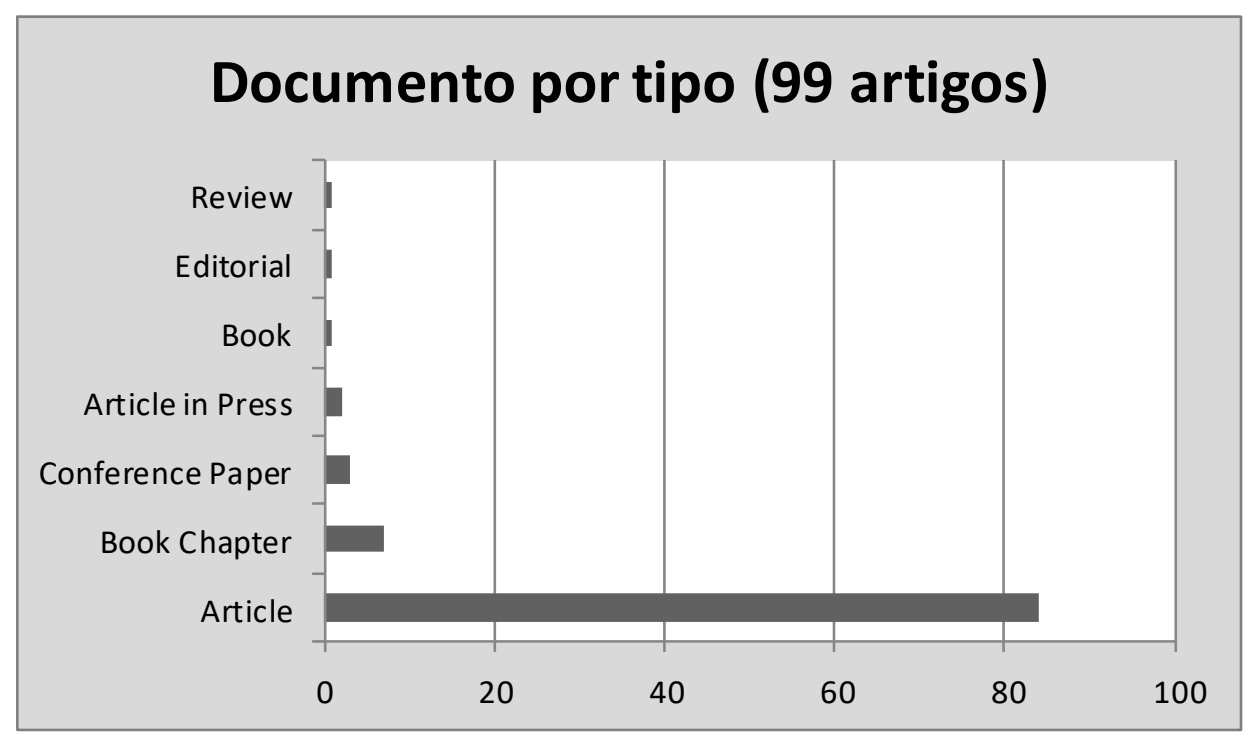

Fonte: Elaborado pela autora.

\subsubsection{Documentos Publicados por Área}

De acordo com a pesquisa, as áreas que mais concentram publicações sobre o tema em análise foram: Negócios, Gestão e Contabilidade com 41,7\%, Ciências Sociais com 24\%, Ciências Agrícolas e Biológicas com 8,6\%, Ciências Ambientais com também 8,6\% e Economia, Econometria e Finanças com 4,6\% (Figura 10), verificando assim uma grande diversidade de áreas que pesquisam sobre a temática. 
Figura 10. Documentos por área.

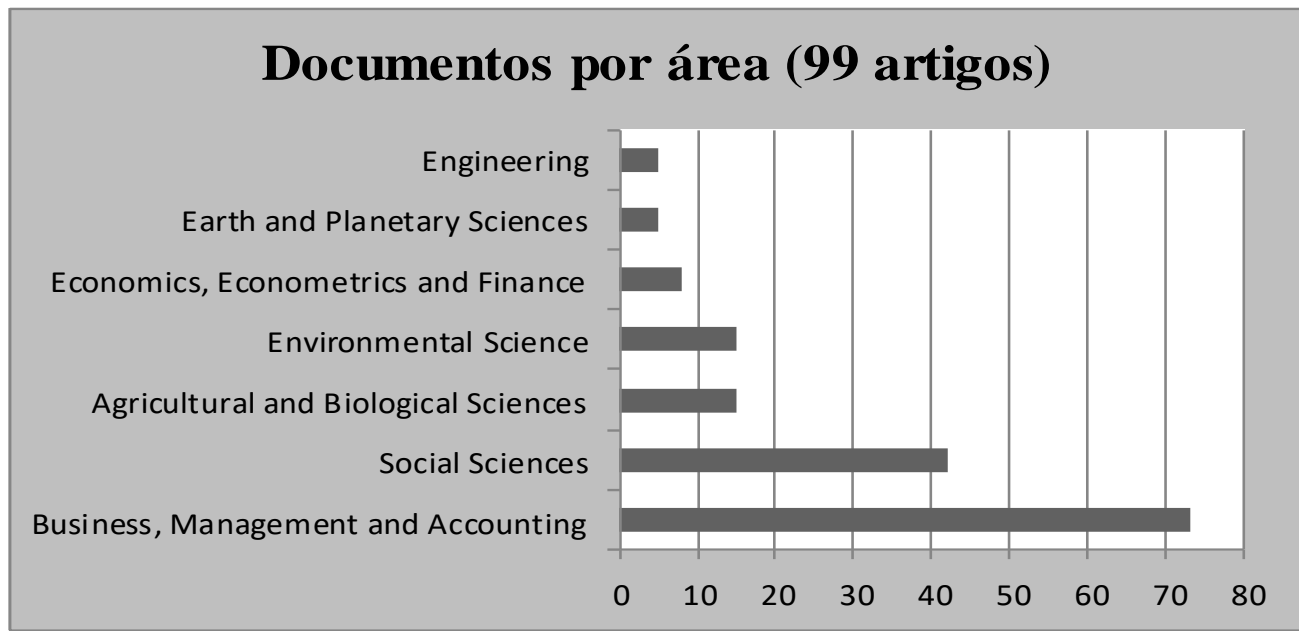

Fonte: Elaborado pela autora

Direcionando a pesquisa para os 20 artigos selecionados, confirmou-se os dados da pesquisa geral, onde a maior concentração está na área de Negócios, Gestão e Contabilidade, seguida da área das Ciências Sociais, depois a área das Ciências Ambientais e por fim a área das Ciências Agrícolas e Biológicas, como mostra a Figura 11.

Figura 11. Documentos por área.

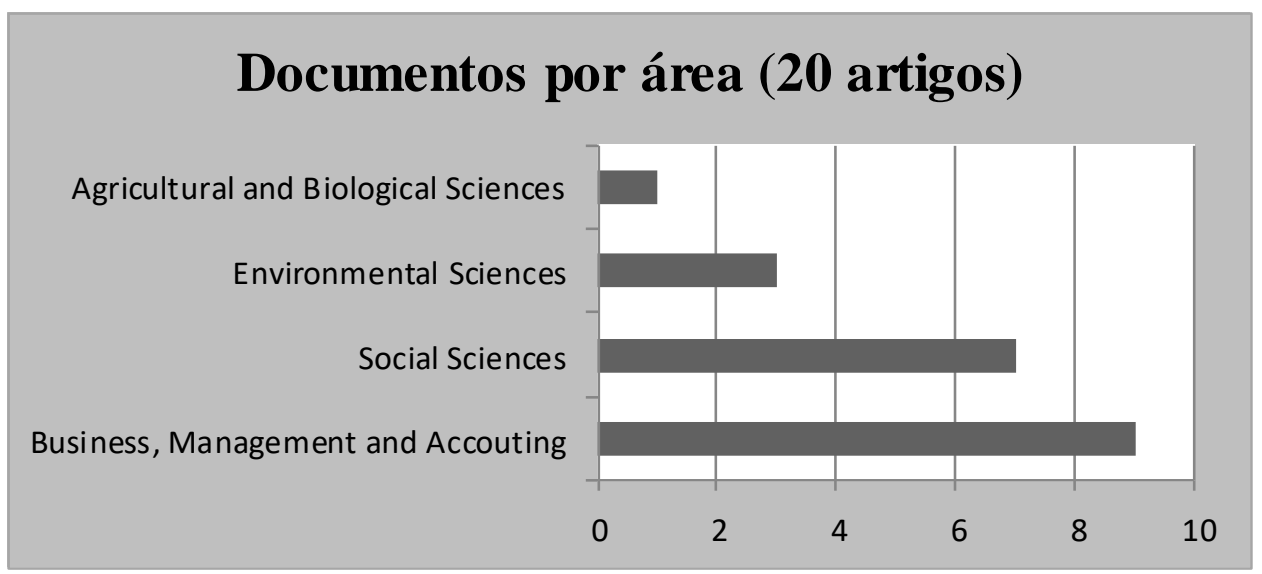

Fonte: Elaborado pela autora

\subsubsection{Temáticas Analisadas por Artigos Selecionados}

Apresentam-se nesta seção os resultados sobre os vinte artigos específicos à temática, selecionados para análise, conforme proposta desse estudo. A partir da análise de cada artigo, feita através da revisão da literatura, percebeu-se que as dimensões e temáticas observadas nos estudos, se concentram em três principais categorias: (i) alimentos locais como 
influenciadores da experiência turística, (ii) alimentos locais como indutores do desenvolvimento da atividade turística e (iii) motivação para compra de alimentos locais e para retorno ao destino (Tabela 2).

Tabela 2. Principais Temáticas abordadas na pesquisa.

\begin{tabular}{|l|l|}
\hline \multicolumn{2}{|c|}{ Temáticas Abordadas } \\
\hline $\begin{array}{l}\text { Alimentos locais como influenciadores } \\
\text { da experiência turística }\end{array}$ & $\begin{array}{l}\text { Björk \& Kauppinen-Räisänen (2014), Björk \& } \\
\text { Kauppinen-Räisänen (2016), Sthapit, Björk, \& } \\
\text { Coudounaris (2017), Wijaya et al. (2013), Tsai } \\
\text { (2016), Sthapit (2017), Sthapit (2019), Antón et } \\
\text { al. (2019), Bukharov \& Berezka (2018), } \\
\text { Frisvoll, Forbord, \& Blekesaune (2016). }\end{array}$ \\
\hline $\begin{array}{l}\text { Alimentos locais como indutores do } \\
\text { desenvolvimento da atividade turística }\end{array}$ & $\begin{array}{l}\text { de la Barre \& Brouder (2013), Chen \& Huang } \\
\text { (2019), Zain et al. (2018), Sidali et al. (2013), } \\
\text { Björk \& Kauppinen-Räisänen (2019), François } \\
\text { et al. (2017), Bukharov \& Berezka (2018). }\end{array}$ \\
\hline $\begin{array}{l}\text { Motivação para compra de alimentos } \\
\text { locais e para retorno ao destino }\end{array}$ & $\begin{array}{l}\text { Madaleno et al. (2018), Akyuz (2019), Sidali et } \\
\text { al. (2013), Frisvoll et al. (2016). }\end{array}$ \\
\hline
\end{tabular}

Fonte: Elaborado pela autora

Sobre a primeira temática analisada, os trabalhos estão relacionados à percepção dos visitantes de destinos turísticos, quanto à influência do consumo dos alimentos locais no resultado final da sua experiência turística, explorando ainda os principais componentes de uma experiência gastronômica considerada memorável para eles.

Já o segundo grupo de temáticas, reflete sobre as questões que envolvem o alimento local como um indutor para o desenvolvimento da atividade turística (de la Barre \& Brouder, 2013), sobretudo o turismo gastronômico e como as tradições relacionadas ao alimento local podem ser utilizadas para posicionar estrategicamente o turismo no mercado (Chen \& Huang, 2019).

Recentemente, Balderas-Cejudo, Patterson, \& Leeson (2019), afirmam que o termo "nicho do turismo" passou a ser utilizado para descrever o desenvolvimento de novos mercados, como o turismo gastronômico ou culinário, que é considerado parte de um processo estrutural mais amplo de diversificação, já que a indústria do turismo busca capturar novos e mais mercados rentáveis. Wolf (2002) usou o termo 'turismo de gastronomia' para 
descrever viagens para pesquisar e desfrutar de comida e bebida preparadas para participar de experiências gastronômicas únicas e memoráveis. O turismo gastronômico também foi referido na literatura turística como turismo alimentar ou turismo culinário.

O terceiro grupo aborda as principais motivações que levam os turistas a decidirem por comprar ou não alimentos locais durante uma viagem (Madaleno, Eusébio, \& Varum, 2018) e se esses alimentos podem influenciar na decisão de um possível retorno ao destino. Autores afirmam também que é possível notar que através do envolvimento alimentar há um aumento na probabilidade de uma pessoa ser motivada a consumir alimentos locais e viajar para buscar novas experiências alimentares ou repetir a experiência vivida (Gurbaskan Akyuz, 2019).

O consumo de alimentos por turistas em um destino serve a muitos propósitos, é multidimensional e dinâmico e, acima de tudo, contribui para as experiências de viagem (Björk \& Kauppinen-Räisänen, 2014). No entanto (Kim et al., 2019, citados por Björk \& Kauppinen-Räisänen, 2014), afirmam que a comida local merece mais atenção acadêmica, já que muitas questões relacionadas ao consumo de alimentos locais pelos turistas permanecem ainda sem resposta.

A literatura mostrou que os encontros relacionados à comida funcionam não apenas para o sustento fisiológico do corpo, mas também como um reforço das experiências globais de destino e que o interesse do visitante e suas preferências por alimentos nos locais de destino podem ser um determinante significativo das escolhas de destino. Neste sentido, Wijaya et al. (2013), postulam a influência das experiências alimentares na percepção dos visitantes, satisfação e intenções de revisitar o destino. A comida atua como uma porta de entrada para os visitantes aprenderem sobre outra cultura através de um envolvimento direto com as culinárias locais em um destino, que difere do que eles têm em casa (Fields, 2002, e Hegarty e O'Mahony, 2001). É evidente que a comida local pode servir como um meio de ajudar os visitantes a apreciar a cultura que prevalece em um destino (Long, 2004).

Entender e apreciar outras culturas envolve adquirir um conhecimento de sua gastronomia (Antón et al., 2019). De fato, um componente-chave da experiência turística vem da comida local, isto é, do turismo culinário ou gastronômico. Os turistas são motivados pela vontade de experimentar a vida real das pessoas locais e desfrutar de uma experiência autêntica da cultura do destino, parte da qual envolve experimentar a comida local. Recentemente, o interesse nesta questão aumentou. O alimento é agora considerado um recurso turístico indispensável e a alimentação na viagem é considerada uma experiência central, com muito valor para os visitantes (Antón et al., 2019). 
Além dos principais produtos turísticos, os atributos culturais locais do destino, como história, patrimônio, incluindo alimentos, contribuem para a popularidade de um destino, segundo os autores Björk e Kauppinen-Räisänen, 2016; Folgado-Fernández, Hernández Mogollón, \& Duarte, 2017; Jalis, Zahari, Zulkifly, \& Othman, 2007; Royo-Vela, 2009; Timothy, 2011, citados por Zain, Zahari, \& Hanafiah, (2018). O alimento como parte da cultura é reconhecido como um dos elementos importantes, um elemento não facilmente ignorado pelos viajantes. A comida se torna um "ponto focal" para a tomada de decisões em viagens e é a atração principal de vários destinos ao redor do mundo (Björk \& KauppinenRäisänen, 2016). Turistas ou viajantes encontram e experimentam as variedades de alimentos e bebidas, e aprendem sobre as culturas alimentares e a herança daquele país ou destino em particular. É inegável que a comida, como elemento cultural, poderia criar e fortalecer a imagem de destino (K. Kim, Hallab \& Kim, 2012, Jalis et al., 2007; Royo-Vela, 2009, citados por Zain et al., 2018).

Com o aumento da competição entre os destinos turísticos, é necessária uma compreensão mais profunda das preferências e tendências dos turistas, para a criação de proposições de valor que contribuam para a atratividade do turismo (Bukharov \& Berezka, 2018). Se a gastronomia local tem características específicas, ela pode fornecer uma base para a diferenciação e colaborar para a vantagem competitiva de um destino.

Assim, a abundância de produtos alimentícios em um mercado globalizado, juntamente com a existência de cadeias de restaurantes internacionais de alimentos em todo o mundo, transformam produtos locais genuínos e autênticos em uma experiência gastronômica memorável cada vez mais desafiadora (Sidali \& Hemmerling, 2014, citados por Antón et al., 2019). Mas mesmo que os turistas se sintam atraídos pela culinária local e estejam ansiosos para desfrutar de uma experiência autêntica e diferente, a experiência real pode ou não, ser memorável.

Compreender as memórias dos turistas de experiências culinárias e gastronômicas é difícil, porém vale a pena, porque a comida pode funcionar como um gatilho para a escolha do destino e pode ajudar os turistas a moldar sua impressão geral de um destino (Björk \& Kauppinen-Räisänen, 2016). Além disso, memórias relacionadas à comida podem tornar os turistas emocionalmente ligados ao destino, aumentando seu nível de envolvimento com ele e, eventualmente, influenciando as intenções de revisita (Gross \& Brown, 2006, Kivela \& Crotts, 2006, citados por Sthapit, 2017) e de indicação do destino para outras pessoas. 


\subsubsection{Abordagens Encontradas nos Estudos}

Os estudos em sua maioria utilizaram um método empírico de abordagem, que necessita uma comprovação prática, usando questionários auto-administrados e entrevistas para recolha dos dados. A maior parte dos estudos realizou pesquisa quantitativa, seguida das pesquisas qualitativas, utilizando o método analítico interpretativo, para suas análises. Identificaram-se ainda dois estudos de revisão de literatura. Houve também um estudo de caráter qualitativo, exploratório, que utilizou a análise textual e visual de materiais promocionais turísticos, produzidos por empresas oficiais de turismo (Figura 12).

Figura 12. Principais Metodologias para Recolha de Dados.

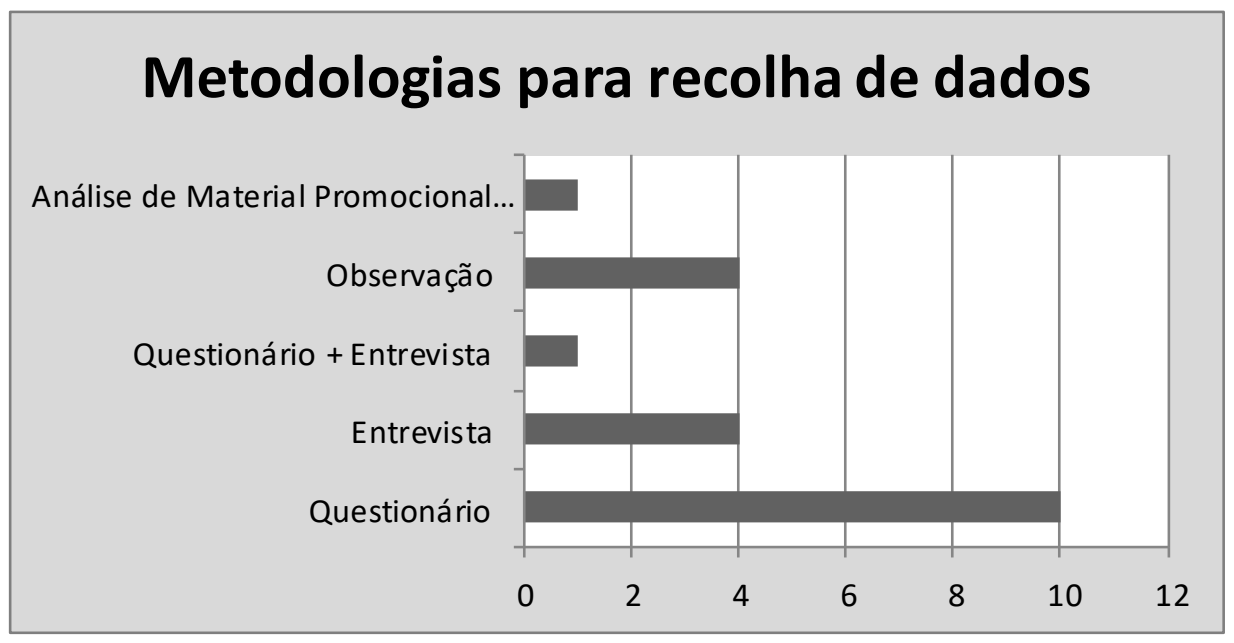

Fonte: Elaborado pela autora.

No estudo de Wijaya et al. (2013), os autores têm como objetivo analisar as experiências dos visitantes ao se envolver com restaurantes locais relacionados a alimentos no destino. Desse modo, eles propõem uma estrutura conceitual de experiências de refeições para visitantes internacionais com a comida local, examinando através de um questionário quantitativo as experiências no decorrer das fases pré, durante e pós-jantar, para medir cada construto. Com a experiência do visitante com o seu núcleo, a estrutura leva em consideração a influência de fatores internos e externos na experiência do visitante.

Sthapit (2017), examina as emoções positivas que os turistas apreciam e o processo de sabor que usam quando relembram experiências gastronômicas passadas. Para isso, utilizou entrevistas semi-estruturadas para reunir as narrativas dos visitantes sobre suas experiências alimentares locais (gastronômicas). Os convites foram enviados por e-mail, para 100 
entrevistados que visitaram Rovaniemi, na Finlândia, através de operadores turísticos locais, indicando assim que os respondentes eram participantes em atividades organizadas.

Assim, observa-se que os estudos em análise adotaram diversas formas de abordagem para a recolha dos dados de suas pesquisas, de acordo com os objetivos propostos.

\subsection{Principais lacunas encontradas nos estudos selecionados}

Após análise criteriosa dos estudos selecionados, pôde-se observar algumas lacunas existentes no campo da investigação, principalmente no que tange às questões metodológicas que foram escolhidas para aplicar nas pesquisas, e quanto a estudos escassos sobre a literatura específica. A partir desse levantamento das principais lacunas encontradas, foram criadas categorias para agrupar esses estudos, que foram descritas como: tamanho reduzido da amostra pesquisada; estudos escassos sobre o tema; limitações geográficas; generalização do estudo; método da recolha de dados; e amostra com mesmo perfil sociocultural (Tabela 3).

Tabela 3. Principais lacunas encontradas.

\begin{tabular}{|c|c|}
\hline \multicolumn{2}{|c|}{ Lacunas Encontradas nos Estudos selecionados } \\
\hline $\begin{array}{l}\text { Tamanho reduzido da } \\
\text { amostra pesquisada }\end{array}$ & $\begin{array}{l}\text { Björk \& Kauppinen-Räisänen (2016), Björk \& Kauppinen- } \\
\text { Räisänen (2019), Sthapit (2017), Sthapit (2019), Gurbaskan } \\
\text { Akyuz (2019). }\end{array}$ \\
\hline $\begin{array}{l}\text { Estudos escassos sobre o } \\
\text { tema }\end{array}$ & Madaleno et al. (2018), Balderas-Cejudo et al. (2019). \\
\hline Limitações geográficas & $\begin{array}{l}\text { Björk \& Kauppinen-Räisänen (2014), Björk \& Kauppinen- } \\
\text { Räisänen (2016), Sthapit, Björk, \& Coudounaris (2017), Tsai } \\
\text { (2016), Sthapit (2017), Antón et al. (2019). }\end{array}$ \\
\hline Generalização do estudo & Madaleno et al. (2018), Wijaya et al. (2013). \\
\hline $\begin{array}{l}\text { Método da recolha de } \\
\text { dados }\end{array}$ & $\begin{array}{l}\text { Wijaya et al. (2013), Tsai (2016), Sthapit (2017), } \\
\text { (2019), Gurbaskan Akyuz (2019). }\end{array}$ \\
\hline $\begin{array}{l}\text { Amostra com mesmo } \\
\text { perfil sociocultural }\end{array}$ & $\begin{array}{l}\text { Wijaya et al. (2013), Sthapit (2017), Sthapit (2019), } \\
\text { Gurbaskan Akyuz (2019). }\end{array}$ \\
\hline
\end{tabular}

Alguns autores sugeriram que pesquisas adicionais deveriam ser realizadas em função das lacunas existentes nos estudos. Balderas-Cejudo et al. (2019) afirmam que sobre o turismo gastronômico, do ponto de vista da análise dos viajantes, há falta de pesquisa sobre o assunto. Além disso, Björk \& Kauppinen-Räisänen (2016), relatam que nas pesquisas devemse usar tamanhos amostrais maiores, pois assim, seria possível aumentar a generalização dos resultados (Sthapit, 2017), não ficando o resultado restrito ou limitado a um perfil específico. 
Para Sthapit (2019), a utilização de um grande tamanho de amostra seria benéfico ao estudo pois aumentaria a heterogeneidade, generalização e confiabilidade dos resultados.

Uma outra grande lacuna apontada nos estudos foi referente às limitações geográficas, pois estes foram realizados em uma região turística específica, num evento ou em um restaurante, restringindo a área pesquisada e limitando a aplicabilidade dos resultados a outros destinos. Para um quadro mais holístico das dimensões que afetam as experiências gastronômicas e a escolha do destino, é necessário ampliar os limites geográficos das pesquisas, sabendo-se que existem outros ambientes alimentares que poderiam ser pesquisados, como mercados de alimentos locais, mercearias, dentre outros (Björk \& Kauppinen-Räisänen, 2014). Sthapit (2017) afirma que as descobertas do seu estudo são altamente específicas do destino e a capacidade de generalizar os resultados é limitada, já que os dados foram coletados apenas pelos visitantes de uma região específica.

A metodologia da recolha de dados também foi apontada como uma grande lacuna nas pesquisas já realizadas, principalmente alguns estudos que utilizaram apenas questionários estruturados e fizeram análises quantitativas. Estes perceberam que algumas respostas psicológicas dos turistas ao consumir alimentos locais foram difíceis de avaliar (Tsai, 2016) apenas através de estudos quantitativos. O uso de uma única abordagem de pesquisa pode ser inadequado para abordar a complexidade da experiência do visitante (Palmer, 2010, citado por Wijaya et al., 2013). A adoção de uma gama maior de métodos de pesquisa pode superar essa limitação de pesquisa (Sthapit, 2017).

Com base nisto, qualquer investigação empírica deve ser sistemática e rigorosa para abranger as relações complexas entre os vários estágios, fatores e resultados da experiência gastronômica do visitante (Wijaya et al., 2013). Reconhece-se que é fundamental selecionar uma metodologia apropriada, com vistas a assegurar que todos os objetivos sejam alcançados.

Muitos dos estudos relatam também que suas pesquisas foram realizadas em um destino turístico específico, ou um local, onde os entrevistados possuíam um perfil sociocultural bastante similar, o que também dificulta a aplicabilidade do estudo para outro grupo diferenciado.

\section{Considerações Finais}

Este artigo teve como principal objetivo realizar uma revisão da literatura sobre as comidas locais como vetores da experiência turística, e identificar e as principais lacunas nos estudos já realizados, desde 2003 até abril de 2019. 
Constatou-se que a gastronomia local pode ser importante fonte de receita para os destinos turísticos, porque a demanda por experiências de consumo de alimentos é baseada não apenas em alimentos, mas em outros fatores como necessidades sociais, busca de experiências novas e excitantes e qualidade de serviço (Tsai, 2016). Portanto, a culinária local pode fornecer um meio crucial para representar e transmitir a cultura de um local, proporcionando aos turistas experiências inesquecíveis e a oportunidade de fortalecimento do destino.

Verificou-se então, que as principais lacunas existentes nos estudos, se referem principalmente às questões metodológicas, que podem ser realizadas em estudos futuros para atingir objetivos mais alargados. Recomenda-se que outros estudos possam ser realizados em outras regiões geográficas, com diferentes populações e com um número maior de entrevistados, para melhorar a compreensão das emoções provocadas pelo consumo de comida local (culinária). Sugere-se também que sejam incluídos métodos qualitativos, como entrevistas com grupos focais para complementar a falta de informação em uma pesquisa quantitativa.

Sugere-se também que sejam realizados estudos que façam um mapeamento de outras experiências culturais realizadas, que estejam ligadas direta ou indiretamente à gastronomia local, como por exemplo, a experiência vivida por um turista que visita uma plantação de um determinado alimento local, podendo colher este alimento e posteriormente saboreá-lo.

Assim, conclui-se afirmando que a experiência gastronômica pode ser considerada como a parte principal de uma viagem e baseia-se nas emoções dos turistas, adquiridas no consumo. Se essa experiência for negativa, pode ter um significado maior do que a herança cultural percebida. Estudos futuros devem adotar uma visão crítica das dimensões das emoções de consumo alimentar e incluir outras dimensões que possam impactar as memórias turísticas de experiências gastronômicas.

\section{Referências}

Aguiar, EP \& Melo, SM. (2020). Turismo e inovação territorial: Um olhar na perspectiva gastronômica. Research, Society and Development, 9(7). http://dx.doi.org/10.33448/rsdv9i7.3670

Akyuz, BG. (2019). Factors that influence local food consumption motivation and its effects on travel intentions. Anatolia, OO(00), 1-10. https://doi.org/10.1080/13032917.2019.1595072 
Antón, C, Camarero, C, Laguna, M \& Buhalis, D. (2019). Impacts of authenticity, degree of adaptation and cultural contrast on travellers' memorable gastronomy experiences. Journal of Hospitality Marketing and Management, 28(07), 1-22.

https://doi.org/10.1080/19368623.2019.1564106

Balderas-Cejudo, A, Patterson, I \& Leeson, GW. (2019). Senior Foodies: A developing niche market in gastronomic tourism. International Journal of Gastronomy and Food Science, 16(April), 100152. https://doi.org/10.1016/j.ijgfs.2019.100152

Björk, P., \& Kauppinen-Räisänen, H. (2014). Culinary-gastronomic tourism - a search for local food experiences. Nutrition and Food Science, 44(1): 294-309.

https://doi.org/10.1108/NFS-12-2013-0142

Björk, P \& Kauppinen-Räisänen, H. (2016). Local food: a source for destination attraction. International Journal of Contemporary Hospitality Management, 28(1), 177-194.

Björk, P \& Kauppinen-Räisänen, H. (2019). Destination foodscape: A stage for travelers' food experience. Tourism Management, 71(November 2018), 466-475. https://doi.org/10.1016/j.tourman.2018.11.005

Bukharov, I \& Berezka, S (2018). The role of tourist gastronomy experiences in regional tourism in Russia. Worldwide Hospitality and Tourism Themes, 10(4), 449-457.

Chen, Q., \& Huang, R. (2019). Understanding the role of local food in sustaining Chinese destinations. Current Issues in Tourism, 22(5), 544-560.

https://doi.org/10.1080/13683500.2018.1444020

de la Barre, S \& Brouder, P. (2013). Consuming stories: Placing food in the arctic tourism experience. Journal of Heritage Tourism, 8(2-3), 213-223.

https://doi.org/10.1080/1743873X.2013.767811

Fields, K. (2002). Demand for the gastronomy tourism product: Motivational factors. In A.-M. Hjalager, \& G. Richards (Eds.), Tourism and gastronomy (pp. 36-50). London: 
Routledge.

François, KT, Massow, MV \& Joppe, M. (2017). Strengthening farmers-hotel supply chain relationships: A service management approach. Tourism Planning \& Development, 14:2, 198219. https://doi.org/10.1080/21568316.2016.1204359

Frisvoll, S, Forbord, M \& Blekesaune, A. (2016). An Empirical Investigation of Tourists' Consumption of Local Food in Rural Tourism. Scandinavian Journal of Hospitality and Tourism, 16(1), 76-93. https://doi.org/10.1080/15022250.2015.1066918

Gurbaskan Akyuz, B. (2019). Factors that influence local food consumption motivation and its effects on travel intentions. Anatolia, 00(00), 1-10. https://doi.org/10.1080/13032917.2019.1595072

Hegarty, J \& O’Mahoney, G. (2001). Gastronomy: A phenomenon of cultural expressionism and an aesthetic for living. International Journal of Hospitality Management, 29(1): 3-13.

Long, L. (2004). Culinary tourism: A folkloristic perspective on eating and otherness. Culinary Tourism, The University Press of Kentucky, Lexington, KY.

Madaleno, A, Eusébio, C \& Varum, C. (2018). Purchase of local food products during trips by international visitors. International Journal of Tourism Research, 20(1), 115-125. https://doi.org/10.1002/jtr.2167

Sidali, KL, Kastenholz, E \& Bianchi, R. (2013). Food tourism, niche markets and products in rural tourism: combining the intimacy model and the experience economy as a rural development strategy. Journal of Sustainable Tourism, http://dx.doi.org/10.1080/09669582.2013.836210

Sthapit, E. (2017). Exploring tourists' memorable food experiences: a study of visitors to Santa's official hometown. Anatolia, 28(3), 404-421. https://doi.org/10.1080/13032917.2017.1328607

Sthapit, E. (2019). Memories of gastronomic experiences, savoured positive emotions and 
savouring processes. Scandinavian Journal of Hospitality and Tourism, 19(2), 115-139. https://doi.org/10.1177/0047287510385467

Sthapit, E, Björk, P \& Coudounaris, DN. (2017). Emotions elicited by local food consumption, memories, place attachment and behavioural intentions. Anatolia, 28(3), 363380. https://doi.org/10.1080/13032917.2017.1322111

Tsai, C.-T. (Simon). (2016). Memorable Tourist Experiences and Place Attachment When Consuming Local Food. International Journal of Tourism Research, 18(January), 536-548. https://doi.org/10.1002/jtr

Wijaya, S, King, B, Nguyen, TH \& Morrison, A. (2013). International visitor dining experiences: A conceptual framework. Journal of Hospitality and Tourism Management, 20, 34-42. https://doi.org/10.1016/j.jhtm.2013.07.001

Wolf, E. (2002). Culinary tourism: A tasty economic proposition. Retrieved May 9, 2005, from. http://www.culinarytourism.org/faq.php

Zain, NAM, Zahari, MSM \& Hanafiah, MH. (2018). e-Review of Tourism Research (eRTR), Vol. 15, No. 1, 2018 http://ertr.tamu.edu. 15(1), 1-20.

Porcentagem de contribuição de cada autor no manuscrito

Renata Ramos Vieira dos Reis - 100\% 